\title{
ПСИХОЛОГИЧЕСКИЕ ОСОБЕННОСТИ ПРОФЕССИОНАЛЬНОЙ ИДЕНТИФИКАЦИИ СОТРУДНИКОВ СЛЕДСТВЕННОГО КОМИТЕТА: МАТЕРИАЛЫ ЭМПИРИЧЕСКОГО ИССЛЕДОВАНИЯ
}

\author{
Ермаков Павел Николаевич \\ Березин Игорь Гарриевич
}

В данной статье представлены эмпирические материалы по исследованию психологических особенностей профессиональной идентификации сотрудников Следственного комитета. Профессиональная идентификация рассматривается как прочесс развития личностной рефлексии профессиональной идентичности себя в соотношении с «эталонным образом» сотрудника соответствующей организации с целью достижения позитивной профессиональной самоидентификации. В качестве респондентов выступили сотрудники следственных управлений Следственного комитета Российской Федерации, дислоцированных на территории Южного и Северо-Кавказского федеральных округов (1286 респондентов).

Для выявления особенностей профессиональной идентичности сотрудников Следственного комитета был использован челый ряд методик. Были разработаны авторские анкеты по выявлению уровней рефлексии профессиональной идентификации сотрудников Следственного комитета, а также проведены психометрические методики (диагностика мотивационных ориентаций в межличностных коммуникациях (И. Д. Ладанов, В. А. Уразаева), методика личностного дифференциала (вариант, адаптированный в НИИ им. В. М. Бехтерева, 2007), диагностика реальной структуры ченностных ориентаций личности (С. С. Бубнова), экспресс-диагностика системно-характерологических отношений личности (Е. Л. Касьяник, Е. С. Макеева), исследование деятельностной мотивационной структуры (К. Замфир), методика по определению уровня конфликтоустойчивости, диагностика эмочиональных барьеров в межличностном общении (В. В. Бойко).

Диагностические результаты позволили выявить различные стратегии профессиональной идентификации сотрудников, принимавших участие в исследовании. Полученные данные показывают, как профессиональная идентификация влияет на уровень профессиональной активности и степень профессиональной самореализации. B статье также описаны барьеры (npenяmствия и затруднения), которые рефлексируются (осознаются) сотрудниками 
как то, что мешает им соответствовать эталонным характеристикам и обрести гармоничные отношения с коллегами и руководством.

Ключевые слова: идентичность, идентификачия, активность, стратегия, смысловая сфера, смысловые образования, самореализация, личностные ченности, профессиональная направленность, ценностно-смысловые барьеры.

Актуальность материалов, представленных в данной статье, обусловлена возрастающей потребностью государства и общества в повышении эффективности деятельности сотрудников Следственного комитета России. Будучи сравнительно новой структурой в системе отечественных государственных силовых институтов, отвечающих за обеспечение различных аспектов функционирования правового государства, Следственный комитет ставит перед психологической наукой задачи, сформулированные в Федеральном законе «О Следственном комитете Российской Федерации» 28.12.2010 № 403-Ф3, и прежде всего это обеспечение оперативного и качественного расследования преступлений. Законодательно определенные приоритеты в деятельности Следственного комитета в свою очередь вызывают необходимость совершенствования деятельности его сотрудников, и, в частности, его кадрового обеспечения, разработки и проведения адекватной ситуации кадровой политики. Как отмечается в Концепции развития следственного управления Следственного комитета России, процесс организации работы Следственного комитета должен сопровождаться адекватным решением кадровых проблем.

Особый раздел кадровых проблем связан с поиском психологических механизмов активизации руководителем личностного и профессионального ресурса сотрудников. Использование таких механизмов в реальной практике управленцев в работе СК России позволит увеличить потенциал осознанной активности сотрудников в профессиональной самореализации, поможет преодолеть внутренние конфликты, связанные с проживанием и принятием себя в профессии, выявить и рефлексировать противоречия, возникающие в процессе профессионализации в современных социальноэкономических условиях между силовыми структурами и различными социальными группами населения.

В контексте одного из таких подходов к решению данной проблемы может быть рассмотрена профессиональная идентификация как процесс развития личностной рефлексии профессиональной идентичности себя в соотношении с «эталонным образом» сотрудника соответствующей организации с целью достижения позитивной профессиональной самоидентификации. В современной психологии есть большое количество исследований, ориентированных на 
изучение профессиональной идентификации (Т. Ю. Базаров, О. Н. Бурмистрова, А. Л. Журавлев, Л. Г. Ковалев, Р. Т. Кричевский, С. А. Липатов). Несмотря на активные исследования этой проблемы, как в отечественной, так и в зарубежной психологии наблюдается очевидный дефицит работ, направленных на выявление ее специфики у тех, кто непосредственно работает в силовых структурах, и в частности у сотрудников Следственного комитета. В основном эти работы посвящены специфике деятельности государственных служащих, представителей бизнеса, сотрудников промышленных предприятий и торговых учреждений, педагогов.

Для выявления особенностей профессиональной идентичности сотрудников Следственного комитета был использован целый ряд методик. Были разработаны авторские анкеты по выявлению уровней рефлексии профессиональной идентификации сотрудников Следственного комитета, а также были проведены психометрические методики (диагностика мотивационных ориентаций в межличностных коммуникациях (И. Д. Ладанов, В. А. Уразаева), методика личностного дифференциала (вариант, адаптированный в НИИ им. В. М. Бехтерева, 2007), диагностика реальной структуры ценностных ориентаций личности (С. С. Бубнова), экспресс-диагностика системнохарактерологических отношений личности (Е. Л. Касьяник, Е. С. Макеева), исследование деятельностной мотивационной структуры (К. Замфир), методика по определению уровня конфликтоустойчивости, диагностика эмоциональных барьеров в межличностном общении (В. В. Бойко). Полученные и проанализированные эмпирические данные позволили сделать следующие выводы.

В нашем исследовании в качестве респондентов выступили сотрудники следственных управлений Следственного комитета Российской Федерации, дислоцированных на территории Южного и Северо-Кавказского федеральных округов (1286 респондентов). Необходимо отметить, что средний возраст следователя составляет 26 лет, возраст следователя-криминалиста составляет 34 года, средний возраст инспектора отдела процессуального контроля - 32 года.

Для выявления особенностей профессиональной идентификации, нами (как было уже сказано ранее) были составлены две анкеты:

1. Первая анкета была ориентирована на выявление «эталонных характеристик», которые должны быть присущи сотруднику Следственного комитета, которые ориентируют его поведение на «законы» корпоративного сообщества и составляют «фундамент» корпоративной культуры. Данная анкета состояла из 16 вопросов, по 4 вопроса в каждой из 4 предлагаемых шкал: 1-я шкала - вопросы о поле, возрасте, должности, стаже работы; 2-я шкала связана с вопросами на выявление уровня информированности сотрудника о требованиях нормативно-регламентирующих документов по поводу личностных особенностей сотрудников Следственного комитета; 3-я шкала выявляет 
представление о том, какие качества сотрудника являются наиболее важными для его профессиональной успешности (4 качества физической подготовки; 4 качества, связанные с интеллектуальным развитием; 4 качества, связанные с эмоционально-волевыми характеристиками; 4 качества, связанные с ценностными ориентациями); 4-я шкала связана с выявлением представлений сотрудника о взаимоотношениях в корпоративном сообществе (отношения с начальством, отношения с подчиненными, отношения с противоположным полом на службе, отношения с сотрудниками более старшего возраста).

2. Вторая анкета ориентирована на выявление различных видов идентификации, которые присущи сотрудникам Следственного комитета, а также этапов вовлеченности сотрудника в профессиональное сообщество, наличия барьеров «вовлеченности» в профессиональное сообщество. Анкета состоит из 12 вопросов, которые ориентированы на выявление особенностей профессиональной идентификации, организационной идентификации, корпоративной идентификации, дезидентификации, опережающей идентификации, нейтральной идентификации, амбивалентной идентификации.

Анкетирование проводилось с целью выявить специфику ценностных установок участников исследования (позитивные или негативные) по отношению к ценностям, позиционируемым как приоритетным для сотрудников Следственного комитета регламентирующими документами.

Ответы оценивались с помощью частотного анализа и контент-анализа. Были определены следующие параметры:

- позитивное или негативное отношение к своей профессии (профессиональная идентификация);

- позитивное или негативное отношение к конкретной организации, в которой работает сотрудник (организационная идентификация).

Далее было проведено выявление стадии идентификации по принятию профессиональных эталонов как личностной ценности. Для этого были выделены категории (составлена категориальная сетка), которые указывали на следующие особенности личностного развития сотрудника:

- эмоционально-волевые (способность к эмпатийному взаимодействию, сочувствию, сопереживанию и пониманию других людей; зрелость эмоциональной сферы; развитые самоконтроль, целенаправленность и интегрированность личности; высокая толерантность к фрустрациям);

- когнитивные (интеллектуальность; высокий уровень самоанализа и рефлексии, выраженные в дифференцированном восприятии профессиональных препятствий, барьеров и осознании внутренних конфликтов);

- мотивационные (направленность на сферы профессиональной жизни, обучения и образования; терминальные ценности «сохранение собственной индивидуальности», «развитие себя»). 
Были выделены и охарактеризованы эталонные характеристики (или, как их еще называют в последние годы - эталонные профессиональные компетенции и универсальные действия). Выявленные параметры (соответствие представлений сотрудника о своем собственном профессиональном «образе» и его соответствие эталонным характеристикам) позволили выделить и охарактеризовать уровни профессиональной и организационной идентификации сотрудников.

В дальнейших этапах исследования принимали участие те сотрудники, у которых был выявлен средний уровень профессиональной идентификации.

В процессе анализа ответов участников исследования, ориентированных на выявление особенностей профессиональной и организационной идентификации, были выявлены барьеры (препятствия и затруднения), которые рефлексируются (осознаются) сотрудниками как то, что мешает им соответствовать эталонным характеристикам и обрести гармоничные отношения с коллегами и руководством.

Контент-анализ ответов на предложенные сотрудникам вопросы двух анкет позволил выявить стратегии профессиональной идентификации сотрудников. Эти стратегии мы рассматривали как производную от смысложизненных стратегий и стратегий профессионального поведения. Мы объединили их в две группы: «позитивные» и «негативные».

Проведенное сравнение позволило перейти к следующему этапу исследования: анализу результатов психометрических диагностик у сотрудников с разными стратегиями профессиональной идентификации и описанию симптомокомплексов психологических характеристик для лиц с разными стратегиями профессиональной идентификации.

В группах с «позитивными» стратегиями идентификации выявлена значимая корреляция $(r=0,844$, при $p \leq 0,01)$ с ориентацией на социальную активность для достижения жизненного успеха. Анализ данных этой же группы выявил статистически значимую взаимосвязь между личностным дифференциалом (который свойственен тем, у кого позитивная профессиональная идентификация) и такими ценностями, как уважение других ( $r=0,749$, при $p \leq 0,05)$, социальный статус ( $r=0,658$, при $p \leq 0,05)$, материальное благополучие $(r=0,727$, при $\mathrm{p} \leq 0,01)$ и возможность заниматься любимым делом $(r=0,888$, при $p \leq 0,001)$. Положительная корреляция обнаружена также между профилем отношение к делу с отношением к другим $(r=0,770$, при $p \leq 0,01)$ и социальным статусом $(r=0,739$, при $p \leq 0,01)$. В процессе обработки результатов была выявлена отрицательная взаимосвязь между амбивалентной стратегией профессиональной идентификации и конфликтоустойчивостью $(r=-0,843$, при $p \leq 0,01)$. Чем выше уровень конфликта между внутренней и внешней трудовой мотивацией, тем ниже конфликтоустойчивость, и тем 
выше вероятность, что в условиях повышенной эмоциональной напряженности сотрудник будет плохо владеть собой, может провоцировать конфликты как с сослуживцами, так и с другими участниками профессионального взаимодействия. Именно для этих респондентов была характерна «отрицательная» стратегия. Полученные данные свидетельствуют о том, что для сотрудников с «позитивными» стратегиями профессиональной идентификации характерна направленность на то, чтобы люди, общество видели и понимали, что их труд приносит реальную пользу и должен высоко оцениваться как важная и общественно значимая деятельность.

Сотрудники Следственного комитета, которые имеют позитивную профессиональную идентификацию среднего уровня, реализуют ее в следующих стратегиях:

- нейтральная стратегия с элементами негативизма, рефлексия барьера вовлеченности («я понимаю, что эталоны нужны, но я сам им не соответствую и все вокруг меня им не соответствуют, но я надеюсь на позитивные преобразования в стране и в Следственном комитете, которые помогут сотрудникам в большей степени соответствовать тому, что от них ждут общество и население») - 3 \%;

- нейтральная стратегия с позитивной тенденцией («я понимаю, что эталоны нужны, но я сам им не соответствую, однако со мной работают те, кто этим эталонам соответствует. Я надеюсь, что через какое-то время я сам стану более совершенным») - 6 \%;

- амбивалентная стратегия, наличие барьера вовлеченности (рефлексия внутренних факторов), рассогласование между профессиональной и организационной идентичностью («я знаю, что в нашей организации работают люди, которые не соответствуют эталонам, и это мешает мне самому им соответствовать, но в других подразделениях Следственного комитета все более благополучно и у меня есть шанс в будущем в большей степени соответствовать желаемым образцам») - $11 \%$;

- позитивная стратегия («я частично соответствую эталону, многие мои коллеги тоже, однако мне не совсем понятно, что мы можем делать для достижения полного соответствия») - 63 \%;

- опережающая позитивная стратегия («я частично соответствую эталону, многие мои коллеги тоже и мы готовы проявить активность для дальнейшего профессионального совершенствования; без этого в нашей профессии нельзя») - $17 \%$.

В настоящем исследовании, основной целью которого было выявить, как именно человек ощущает себя частью профессии и сотрудником конкретной организации, были выявлены так называемые «барьеры вовлеченности», которые мы рассматривали как ценностно-смысловые затруднения 
в идентификации себя с профессией и организацией, как то, что мешает человеку в профессиональной самореализации и в обретении гармонии с сослуживцами и руководством.

На основе диагностических данных были выделены два вида ценностносмысловых барьеров, которые препятствуют позитивной профессиональной и организационной идентификации сотрудников Следственного комитета:

- внешние барьеры - «барьеры», препятствующие внешнему (со стороны профессии и организации) стимулированию позитивной профессиональной идентификации, «барьеры» стимулов (отсутствие времени для профессионального совершенствования, перегруженность, отсутствие квалифицированных помощников (экспертов), некомпетентные проверяющие, отсутствие комфорта в организации рабочего места и образа (плохие кабинеты, несовременная форма), небольшая зарплата);

- внутренние барьеры, барьеры «смыслообразования» (стремление повысить престиж профессии в глазах населения, но непонимание, как это сделать; отсутствие реальных эталонов в профессиональной самореализации - расхождение между тем, что требуется, и тем, что существует в реальности).

Внешние и внутренние барьеры существенно влияют на специфику развития профессиональной и организационной идентификации в реальной трудовой деятельности. Наличие этих барьеров необходимо учитывать при описании стратегий профессиональной идентификации сотрудников.

Учет особенностей профессиональной идентификации сотрудников должен стать обязательным компонентом эффективного руководства в условиях работы Следственного комитета. Руководитель, работающий в специфических условиях Следственного комитета, находится в ситуации поиска потенциальных ресурсов сотрудников, активизировав которые, можно добиться более эффективной и продуктивной профессиональной деятельности. Профессиональная идентичность и ее динамическая составляющая, профессиональная идентификация, становятся как раз таким ресурсом.

\section{Литература}

1. Абакумова И. В., Ермаков П. Н. Технологии направленного воздействия по профилактике идеологии экстремизма и терроризма // Сборник материалов 6-й международной научной конференции по проблемам безопасности и противодействия терроризму (11-13 ноября 2010 года, МГУ, Москва). - М., 2010. - С. 181-194.

2. Акимова А. М. Значение квалификационной характеристики должности сотрудника при повышении квалификации и профессиональной переподготовки // Вестник ВИПК МВД России. - 2007. - № 2. - С. 47-49. 
3. Артемова Я. В. Генезис исследований корпоративной идентичности личности в современной науке: Учебное пособие / Под общ. ред. проф. В. С. Агапова. - М.: РУДН, 2010. - 40 с.

4. Артемова Я. В. Корпоративная идентичность личности: сущностные признаки, структура и типология: Монография / Под общ. ред. проф. В. С. Агапова. - М.: РУДН, 2010. - 59 с.

5. Березин И. Г., Брижак 3. И. Психологические основы эффективного управления следственными органами // Юристъ-правовед. - 2010. № 1 (38), - С. 89-92.

6. Бородулькина Т. А. Влияние образа профессии на становление профессиональной идентичности // Проблемы общей и педагогической психологии: Сборник научных трудов Института психологии им. Г. С. Костюка АПН Украины / Под ред. С. Д. Максименко. - К., 2007.

7. Парламентская газета / Круглый стол на тему «Современные подходы к формированию морально-психологических качеств российского полицейского». 25 апреля 2011 года. - 2011.

8. Психология формирования антитеррористических ценностей студентов современного университета: учебник (под ред. И. В. Абакумовой, П. Н. Ермакова). - М.: КРЕДО, 2013. - 352 с.

9. Солнышкина М. Г. Профессиональные стратегии личности: монография. - Москва: Информационно-внедренческий центр «Маркетинг», 2006. - 119 c.

10. Abakumova I. V., Kruteleva L. Ju. Tolerance in the Structure of Life-Sense Strategies of the Modern Youth /The 13th European Congress of Psychology, 2013. - Stockholm, Sweden, 9-12 July 2013.

11. Halpern D. Moral values, social trust and inequality // British Journal of Criminology. - 2001. - Vol. 41. - pp. 236-251.

12. Leung K. Social axioms. The search for universal dimensions of general beliefs about how the world functions // J. of Cross-Cultural psychology. 2002. - Vol. 33. - pp. 286-302. 


\title{
PSYCHOLOGICAL FEATURES OF PROFESSIONAL IDENTIFICATION OF OFFICERS OF THE COMMITTEE OF INQUIRY: MATERIALS OF THE EMPIRICAL STUDY
}

\author{
Ermakov Pavel Nikolaevich \\ Berezin Igor' Garrievich
}

This article brings forward empirical materials of studying professional identification of officers of the Committee of Inquiry. Professional identification is considered as a process of development of personal reflection of professional identity of the Self in correlation with a "reference image" of the employee of a respective organization for the purpose of achieving a positive professional self-identification. Officers of the investigative departments of the Committee of Inquiry of the Russian Federation stationed in the territory of the Southern and North Caucasus federal districts (1286 persons) were respondents.

Quite a number of techniques were used for revealing features of professional identity of officers of the Committee of Inquiry. Author's questionnaires revealing levels of reflection of professional identification of officers of the Committee of Inquiry were developed. The authors have also used psychometric techniques (diagnostics of motivational orientations in interpersonal communications (I. D. Ladanov, V. A. Urazaeva), a personal differential technique (version adapted in the Scientific Research Institute named after V. M. Bekhterev, 2007), diagnostics of a real structure of value guidelines of the person (S. S. Bubnova), express diagnostics of system-characterologic relations of personality (E. L. Kas'ianik, E. S. Makeeva), a study of the motivational structure of activities (K. Zamfir), a technique for revealing the level of conflict tolerance, diagnostics of emotional barriers in interpersonal communication (V. V. Boiko).

Diagnostic results have made it possible to reveal various strategies of professional identification of the officers surveyed in the study. The obtained data shows how professional identification influences the level of professional activity and the extent of professional self-realization. The article also describes barriers (obstacles and difficulties) which are reflected (realized) by officers as that prevents them from corresponding reference characteristics and finding harmonious relations with colleagues and leaders.

Keywords: identity, identification, activity, strategy, sense sphere, sense formations, self-realization, personal values, professional orientation, sense-value barriers.

\section{References}

1. Abakumova I. V., Ermakov P. N. Tekhnologii napravlennogo vozdeistviia po profilaktike ideologii ekstremizma i terrorizma [Technologies of the directed influence on prevention of the ideology of extremism and terrorism]. 
Sbornik materialov 6-i mezhdunarodnoi nauchnoi konferentsii po problemam bezopasnosti i protivodeistviia terrorizmu [Proc. the $\sigma_{\text {th }}$ International Scientific Conference on problems of safety and counteraction to terrorism]. Moscow, MSU Publ., 11-13 November, 2010, pp. 181-194.

2. Akimova A. M. Znachenie kvalifikatsionnoi kharakteristiki dolzhnosti sotrudnika pri povyshenii kvalifikatsii i professional'noi perepodgotovki [Importance of the qualification characteristic of the employee's position in professional development and professional retraining]. Vestnik VIPKMVD Rossii-Bulletin of the All-Russian Institute of Professional Development of the Interior Ministry of Russia, 2007, no. 2, pp. 47-49.

3. Artemova la. V. Genezis issledovanii korporativnoi identichnosti lichnosti $v$ sovremennoi nauke: Uchebnoe posobie [Genesis of researches of corporate identity of the person in modern science: textbook]. Moscow, Peoples' Friendship University of Russia Publ., 2010, 40 p.

4. Artemova la. V. Korporativnaia identichnost' lichnosti: sushchnostnye priznaki, struktura itipologiia:Monografiia [Corporate identity of the person: essential attributes, structure and typology: monograph]. Moscow, Peoples'Friendship University of Russia Publ., 2010, 59 p.

5. Berezin I. G., Brizhak Z. I. Psikhologicheskie osnovy effektivnogo upravleniia sledstvennymi organami [Psychological bases of effective management of investigating bodies]. Iurist"-pravoved - Jurist-Lawyer, 2010, no. 1 (38), pp. 89-92.

6. Borodul'kina T. A. Vliianie obraza professii na stanovlenie professional'noi identichnosti // Problemy obshchei i pedagogicheskoi psikhologii: Sbornik nauchnykh trudov Instituta psikhologii im. G. S. Kostiuka APN Ukrainy [Influence of a profession image on professional identity formation. Problems of general and pedagogical psychology: scientific works of the Institute of Psychology of G. S. Kostiuk of the Academy of Pedagogical Sciences of Ukraine]. Kiev, 2007.

7. Parlamentskaia gazeta [The parliamentary newspaper]. Kruglyi stol na temu "Sovremennye podkhody k formirovaniiu moral'no-psikhologicheskikh kachestv rossiiskogo politseiskogo" [The Round Table"Modern approaches to formation of moral-psychological qualities of the Russian policeman"]. 25 April, 2011.

8. Psikhologiia formirovaniia antiterroristicheskikh tsennostei studentov sovremennogo universiteta: uchebnik (pod red. I. V. Abakumovoi, P. N. Ermakova) [The psychology of forming anti-terrorist values in students of the modern university: textbook (under the editorship of I. V. Abakumova, P. N. Ermakov)]. Moscow, KREDO Publ., 2013, 352 p.

9. Solnyshkina M. G. Professional'nye strategii lichnosti:monografiia [Professional strategies of personality: monograph]. Moscow, "Marketing" InformationImplementation Center Publ., 2006, 119 p. 
10. Abakumova I. V., Kruteleva L. Ju. Tolerance in the Structure of Life-Sense Strategies of the Modern Youth / The 13th European Congress of Psychology, 2013, Stockholm, Sweden, 9-12 July 2013.

11. Halpern D. Moral values, social trust and inequality // British Journal of Criminology, 2001, Vol. 41, pp. 236-251.

12. Leung K. Social axioms. The search for universal dimensions of general beliefs about how the world functions // J. of Cross-Cultural psychology, 2002, Vol. 33, pp. 286-302.

\section{THE USE OF PSYCHOLOGICAL KNOWLEDGE WHEN INVESTIGATING DOMESTIC HOMICIDES}

\section{Kiselev Aleksandr Petrovich}

This article touches upon urgent problems of law-enforcement practice for investigation of the most socially dangerous types of crimes - domestic homicides which form a considerable proportion of all the homicides committed in the territory of the Russian Federation.

Effective investigation of domestic homicides, realization of a complex of measures by authorized state bodies directed on prevention of such crimes is impossible without knowledge of psychological features of such a personality by the law enforcement official. The carried out scientific studying have made it possible to distinguish and generalize these features, to disclose their content.

The article explains psychological features of the person committed domestic homicide, gives opinions of scientists who have developed, studied and researched these spheres, specifies mental abnormalities, their significance and influence on the illegal behavior of the person committed domestic homicide. The author has made an attempt to indicate reasons which lead or may lead to commission of acts of aggression in a family and also designates other external circumstances, subjective factors influencing a choice of a violent way of resolving conflicts. Features of a domestic murderer's behavior after commission of a socially dangerous act are given.

The author uses not only empirical data, but also facts of the investigative and judicial practice which have made it possible to unite practical experience with psychological, criminological researches of personality, in relation to domestic homicides. In this regard, this article is of scientific and practical interest for the experts involved in investigation of domestic homicides and their prevention. 